\title{
From the President
}

Pauletta Brown Bracy, President

Productive

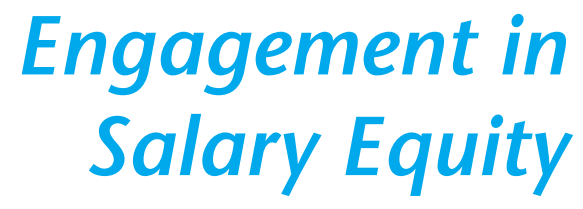

7 ormer American Library Association President Maurice Freedman launched a campaign of awareness and action during his 2002-2003 tenure. He appointed the Better Salaries and Pay Equity Task Force which published a helpful resource, Advocating for Better Salaries and Pay Equity Toolkit (2003). The task force's pay equity advocacy program is founded on the reality of a predominately female workforce which is less well paid than those in fields of comparable work dominated by males. Simply defined, pay equity means that all people receive equal pay for work regardless of race or gender. Salaries of librarians regrettably lag behind those of other professions. In 2002, the average estimated salary of librarians was $\$ 44,430$, according to the U.S. Department of Labor National Occupational Employment and Wages Survey. Pertaining to type of library, the following salaries were posted:

$\begin{array}{ll}\begin{array}{l}\text { Elementary and secondary school } \\ \text { library media specialists }\end{array} & \$ 47,000 \\ \text { Local government (Public) } & \$ 39,080 \\ \text { College and university } & \$ 48,530 \\ \text { Junior college } & \$ 49,650\end{array}$

The Special Libraries Association published a median salary of $\$ 57,000$ in its 2003 salary survey.

Considering librarians to be essential managers, a comparison of our salaries to administrative services managers revealed an annual median salary of $\$ 59,350$. In the related field of network systems, the median projected salary was $\$ 61,390$. The median for computer systems analysts was $\$ 64,890$. An information scientist's salary was projected at $\$ 80,510$. The median salary of library technicians was estimated at $\$ 25,280$.

Statistics maintained at the State Library of North Carolina calculate the average salary of public library directors to be $\$ 60,270$. The minimum salary for a librarian with an M.L.S. is $\$ 32,027$. Hourly rates for library paraprofessionals range from $\$ 8.60$ to $\$ 11.40$, according to educational preparation of high school diploma, two-year degree, and 4-year degree recipients.

Examination of salary data at both national and state levels provides impetus for a statewide consideration of pay equity. Professional library associations in California, New Jersey, and Vermont, have undertaken successful initiatives to equalize pay. Public libraries in Minnesota, New York, Washington, Australia, Canada, and Maryland as well as the library of Southern University of Baton Rouge are case studies of successful efforts.

Undergirding any movement toward pay equity is the notion of demonstrating value. It is critical that we become our own messengers-making the case and delivering it to the appropriate broad-based constituencies. It is a twofold enterprise: the economic value of libraries must be substantiated; and the professional workforce, including library technicians, must be endorsed as individuals who are well qualified to advance the community library agenda. Three tasks are pertinent for preparation: organization, justification; and documentation.

Assertive advocacy leads to progressive pay which is essentially equitable. Any such venture is an undeniably empowering example of productive engagement. 